\title{
Preparation and characterization of $\mathrm{ZnO} / \mathrm{TiO}_{2}$ nanocomposite by Anodization and hydrothermal synthesis
}

\author{
BENKARA Salima', GHAMRI Houda ${ }^{2}$ \\ ${ }^{1}$ Faculty of Science and Applied Science, Larbi Ben M'hidi, University, Oum El Bouaghi 04000, \\ Algeria. \\ Laboratory of active components and materials \\ University Larbi Ben M'hidi Oum El Bouaghi 04000, Algeria
}

${ }^{2}$ Faculty of Science, Hadj Lakhdar University Batna, 05000, Algeria.

E-mail address: sali_benkara@yahoo.fr, Ghamri_houda@yahoo.fr

Keywords: $\mathrm{ZnO}$ nanorods; $\mathrm{TiO}_{2}$

nanotubes; Nanocomposites; Hyd ermal pro ss; Anodic oxidation.

\section{ABSTRACT:}

$\mathrm{ZnO}$ nanorod arrays were deposited by hydrothermal proces ammonia and Zinc nitrate as inorganic precursors, using $\mathrm{TiO}_{2}$ solution by anodization method. The effect of $\mathrm{NH}_{3} \cdot \mathrm{H}_{2} \mathrm{O}$ ad $\Delta \mathrm{Q}_{3}$ concentration on $\mathrm{ZnO}$ nanorods morphology and crystallinity were investic XRL emonstrates that $\mathrm{ZnO}$ nanorods are wurtzite crystal structure preferentially ori nted in c-axis dir ction. The length and the diameter of the $\mathrm{ZnO}$ nanorod range from $1,1 \mu \mathrm{m}$ o $3,4 \mu \mathrm{m}$ and from 250 to $500 \mathrm{~nm}$ respectively.

\section{INTRODUCTION}

One-dimensional (1D) nanostructures, inc ding lanowires, nanotubes and nanorods have attracted significant interests owing to heir un ue geometries. [1] As a kind of 1D oxide material, $\mathrm{ZnO}$ nanorod arrays con dered as important functional oxide nanostructures in a wide area of high-tech log. such as a surface acoustic wave filters [2], ultraviolet laser devices [37 photonic stals [4], photo detectors [5], field-emitting devices [6], sensors [/, oelectric, rerials [8], and solar cell electrodes [9].

Various physical, $c^{1}$ nical, on ectrochemical methods [10-13] have been developed to prepare 1D $\mathrm{ZnO}$. Among nese fabrication nethods, $\mathrm{ZnO}$ nanorods are most commonly grown by vapor phase methor like apor-liquid-solid (VLS), chemical vapor transport, and thermal evaporation [11 "These approaches can produce high quality and vertically aligned nanorods with engt/ of several microns. But, these fabrication procedures require higher temper ure. he comp processes and high cost vacuum equipments are often involved in these techao ies well. Compared with those techniques, chemical solution method is attractive to synthesiz no manostructures because of the low cost equipments, lower growth temperatures, promising caling up, and controlled easily technology of growing high-density nanorods array [16].

A template-assisted approach has been proven to be effective for the growth of nanostructure oxides. A major advantage of using templates is that the dimension of the tubes or rods is set by the size of template and can be varied easily by adjusting preparation conditions. Few efforts have been made on the study of the use of $\mathrm{ZnO}$ nanorods as a template. Yang [17] and Kim [18], demonstrated that inorganic nanotubes can be obtained by using $\mathrm{ZnO}$ nanorods grown from the desired substrates as template. Their procedures involve the use of catalysts, high temperature, and a vacuum technique, leading to increase the cost. Seok et al [19] successfully fabricated aligned $\mathrm{TiO}_{2}$ nanotube arrays by electrodeposition of $\mathrm{ZnO}$ nanorod as a template. In contrast, preparation of $\mathrm{ZnO}$ nanorods using $\mathrm{TiO}_{2}$ nanotubes as templates remain largely unexplored although a few studies. Zhonghai et al [20] prepared $\mathrm{ZnO}$ nanorods embedded 
in highly ordered $\mathrm{TiO} 2$ nanotubes. Ning [21] has reported a strategy to prepare aligned $\mathrm{ZnO}$ nanorod films using $\mathrm{TiO}_{2}$ nanotube array films as template.

Therefore, in the present study we would like to present a detailed investigation on the preparation and characterization of $\mathrm{ZnO} / \mathrm{TiO}_{2}$ nanocomposite film. The $\mathrm{ZnO} / \mathrm{TiO}_{2}$ nanostructured composite film was prepared using two steps: (1) Formation of $\mathrm{TiO}_{2}$ nanotube arrays in $\mathrm{HF}$ solution by anodization method, which is a simple technique to control the structure parameters of $\mathrm{TiO}_{2}$ NTs. (2) Deposition of $\mathrm{ZnO}$ nanorods by hydrothermal process with ammonia and Zinc nitrate as inorganic precursors.

\section{EXPERIMENTAL}

\section{A. Materials and chemicals}

Pieces of Titanium sheets (98\% purity, $0.5 \mathrm{~mm}$ thickness), Zinc $p$ te hexah rite $\left(\mathrm{Zn}\left(\mathrm{NO}_{3}\right) 2.6 \mathrm{H} 2 \mathrm{O}, \mathrm{AR}\right)$, Hydrofluoric acid (HF), Acetone, Nitric acid HN Amn onia solution $\mathrm{NH} 4 \mathrm{OH}$. Distilled water was used in all aqueous solution preparations ano.

\section{B. Preparation of TiO2 nanotubes}

Anodic oxidation method was adopted to prepare 1 nanotube 1 NTs. Prior to anodization, titanium pieces were degreased in an ultras with istilled water for10 min, followed by eroding in a mixture of HF solution, nitric acia and dist / water for $1 \mathrm{~min}$; then cleaned with acetone, rinsed with distilled water and dy ed in air. Anodization is performed in $2 \mathrm{w}$ $\%$ HF solution and distilled water with voltage of 20 olts for 5 il Finally, samples were rinsed and annealed at $450{ }^{\circ} \mathrm{C}$ for $1 \mathrm{~h}$.

\section{Characterization of resulting films samples}

The surface morphology of the film san cs Was observed through scanning electron microscopy (SEM-JEOLJSM-7600 E0438 apparatus). The crystal phase composition of the samples were analyzed by ray fraction XRD, Bruker-Siemens D8- Advance, Cu.K $\alpha$ radiation $\lambda=1.5406 \mathrm{~A}^{\circ}$ ).

\section{RESULTS AND}

Figure 1 is the pres files the $\mathrm{TiO}_{2}$ nanotubes before and after annealing at $450 \mathrm{C}^{\circ}$ for $1 \mathrm{~h}$. As shown in figure 1 b, peaks wit $/$ value of $25.6^{\circ}$ correspond to the crystal plan of anatase (101) phase. And oth peak are corresponding to the titanium substrate, which is similar to the results found $1 \mathrm{~h}$ ar litera res [21] and [22].

Figure 2 pro ts $\mathrm{XP}, 3$ patterns of $\mathrm{ZnO} / \mathrm{TiO}_{2}$ at different hydrothermal temperatures. Except or peaks atanium and titania, the diffraction peaks with $2 \theta$ value of: $32.1^{\circ}, 34.7^{\circ}$ and 2 agy $e$ well $\mathrm{w} / \mathrm{h}$ the wurtzite hexagonal structure with the lattice constants of: $\mathrm{a}=0.32 \mathrm{~nm}$ and $\mathrm{c}=$ ding to the standard JCPDS card (No. 36-1451). Based on the higher (002) XRD peak $(101)$ one, which is usually the highest in all XRD peaks of $\mathrm{ZnO}$ crystal.

XRD pacerns in Figure $2 \mathrm{c}$ show a disappearance of the peaks corresponding to titanium, at high temperature, the formation of $\mathrm{ZnO}$ increases with increasing of reaction rate into aqueous solution, and also the reaction rate between $\mathrm{Ti}$ and $\mathrm{ZnO}$. 


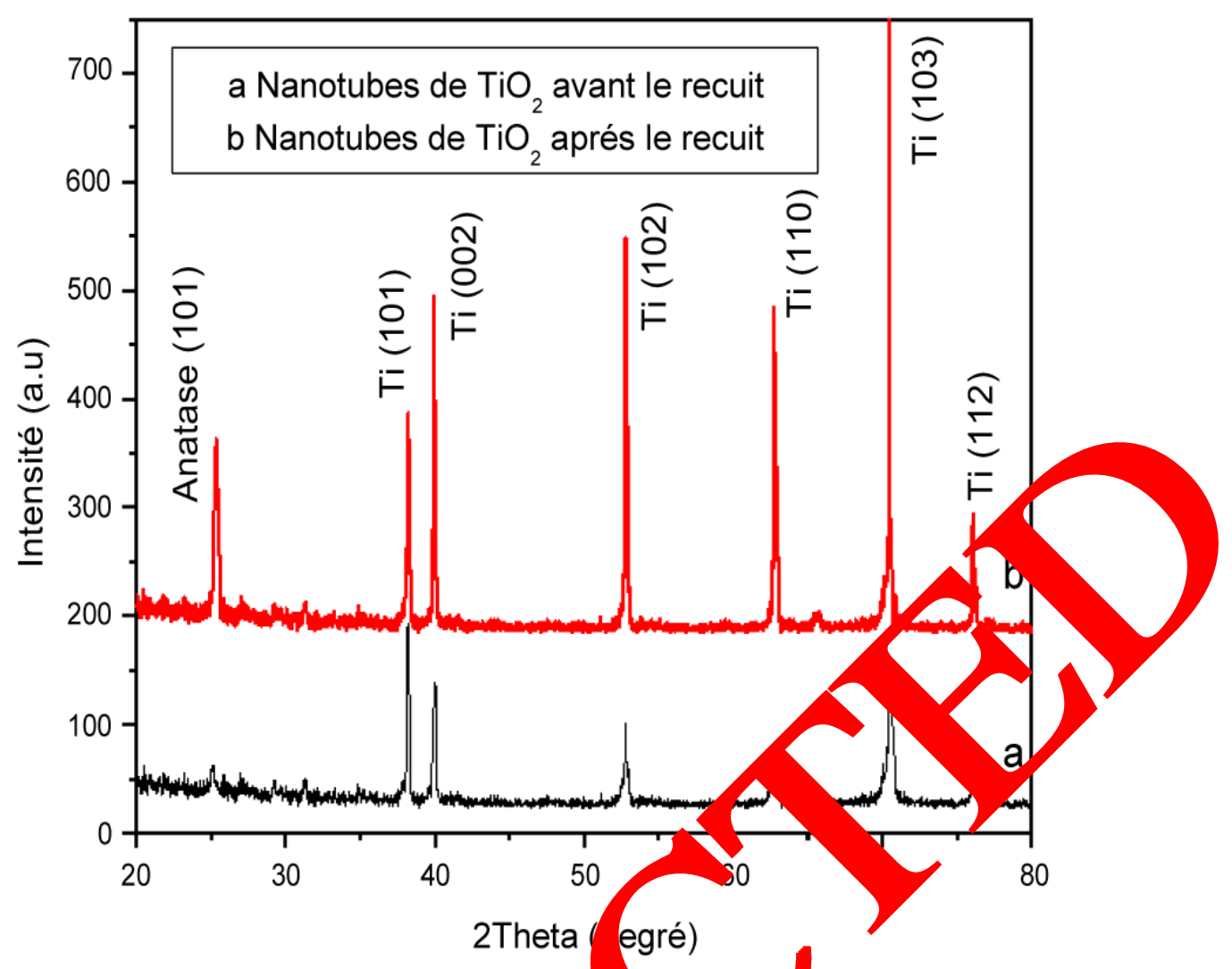

Figure 1. The XRD patterns of $\mathrm{TiO}_{2} \mathrm{Nts}($ efore and 0 ) after annealing.

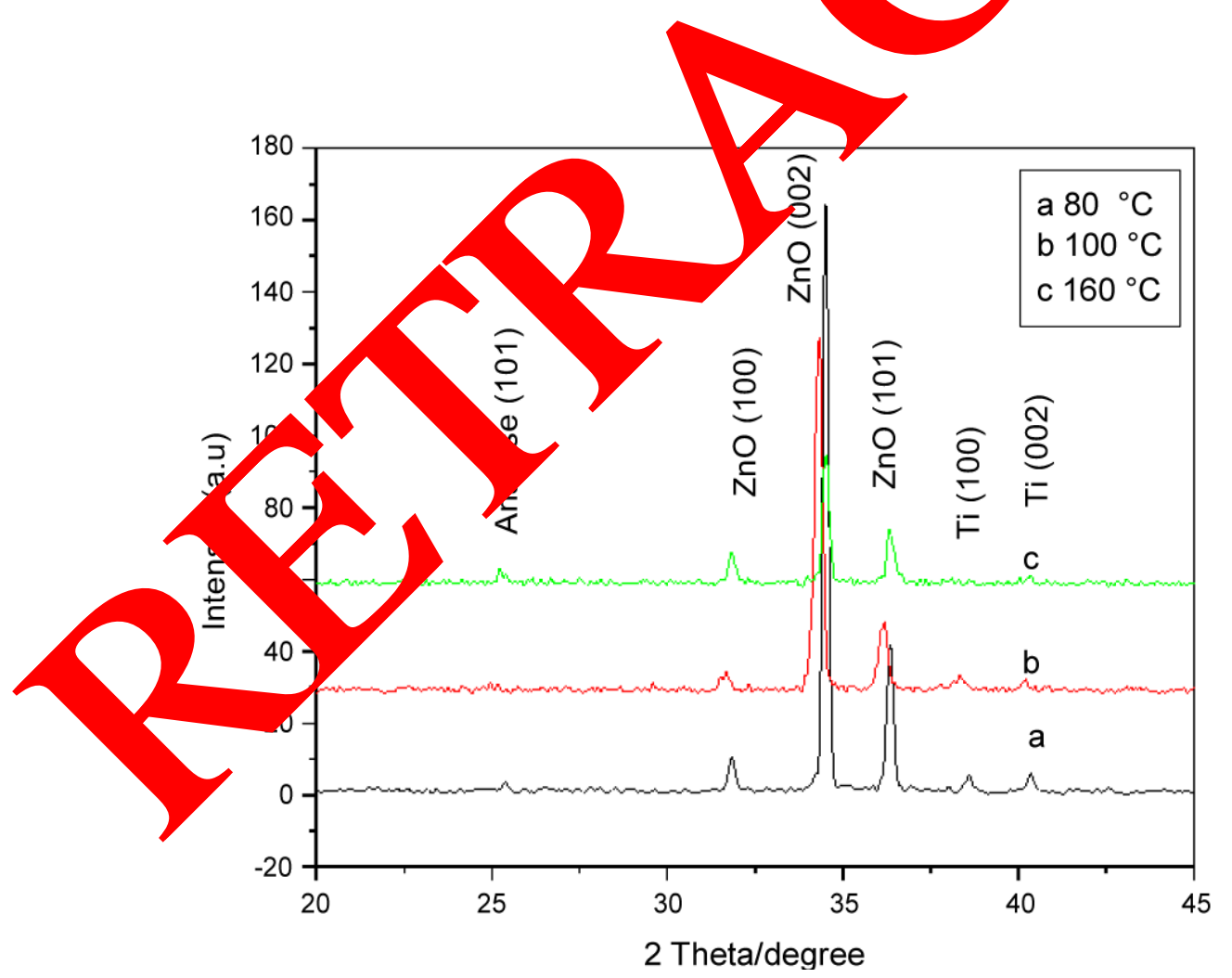

Figure 2. The $\mathrm{XRD}$ patterns of $\mathrm{ZnO} / \mathrm{TiO} 2$ at different hydrothermal temperature: at $80{ }^{\circ} \mathrm{C}(\mathrm{a})$, at $100{ }^{\circ} \mathrm{C}$ (b) and at $160^{\circ} \mathrm{C}$.

No remarkable change in orientation of the films as the amount of ammonia was increased shown in Figure 3 but influenced the intensity of the preferred crystalline orientation. 


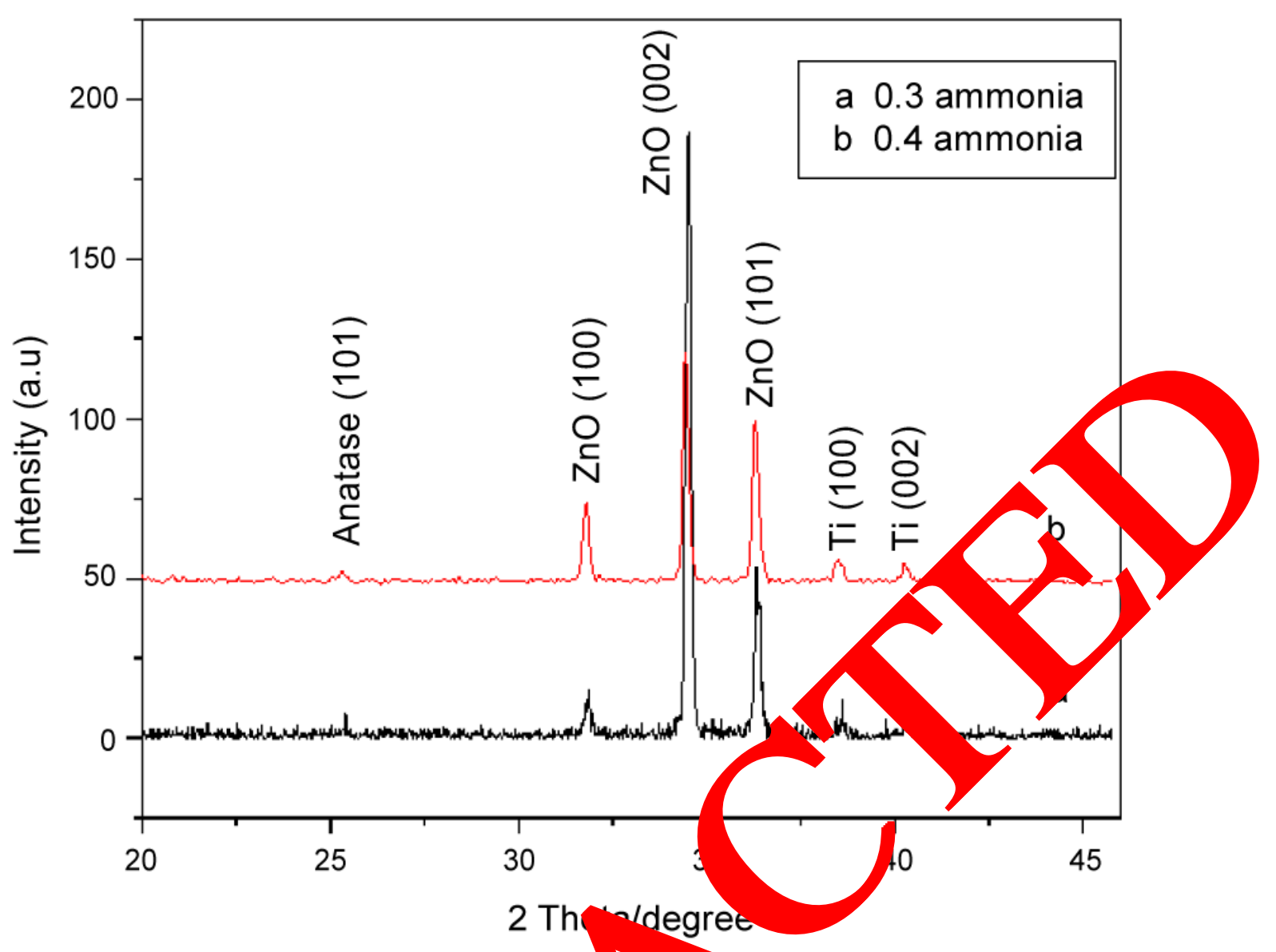

Figure 3. The XRD patterns of $\mathrm{ZnO} / \mathrm{TiO} 2$ ith ty ammonia and (b) 0,4 of ammonia.

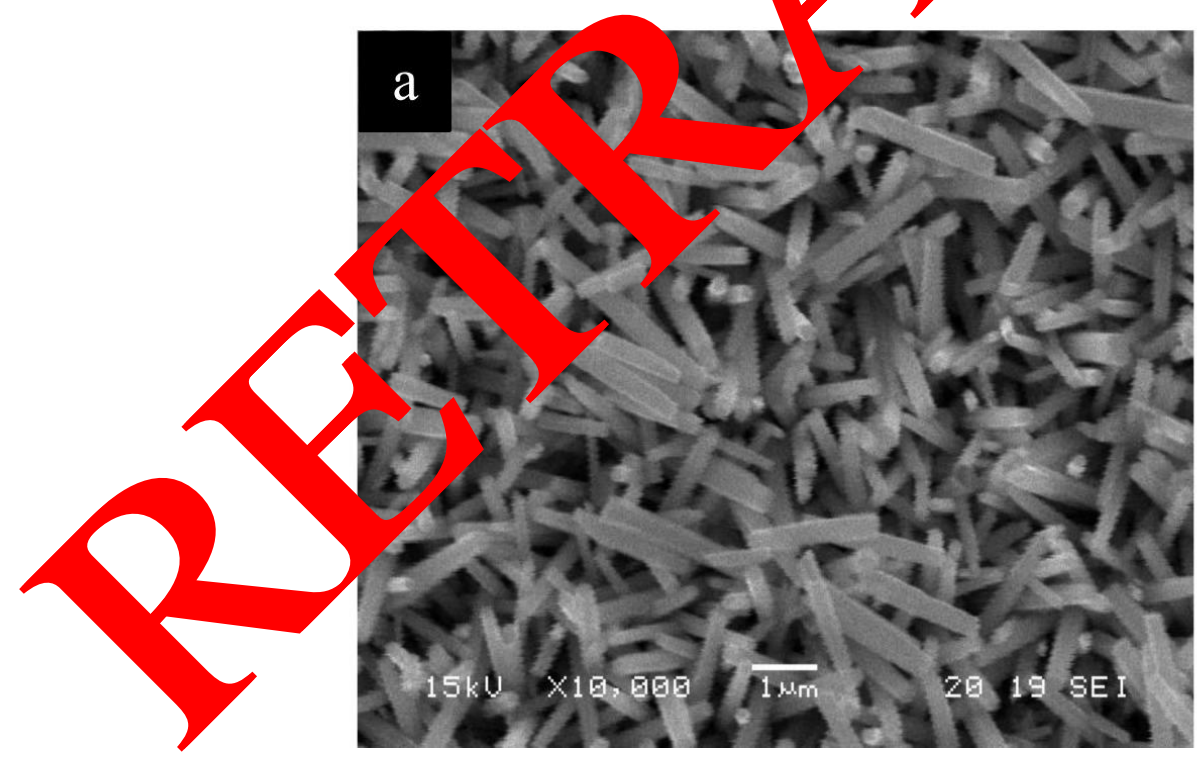




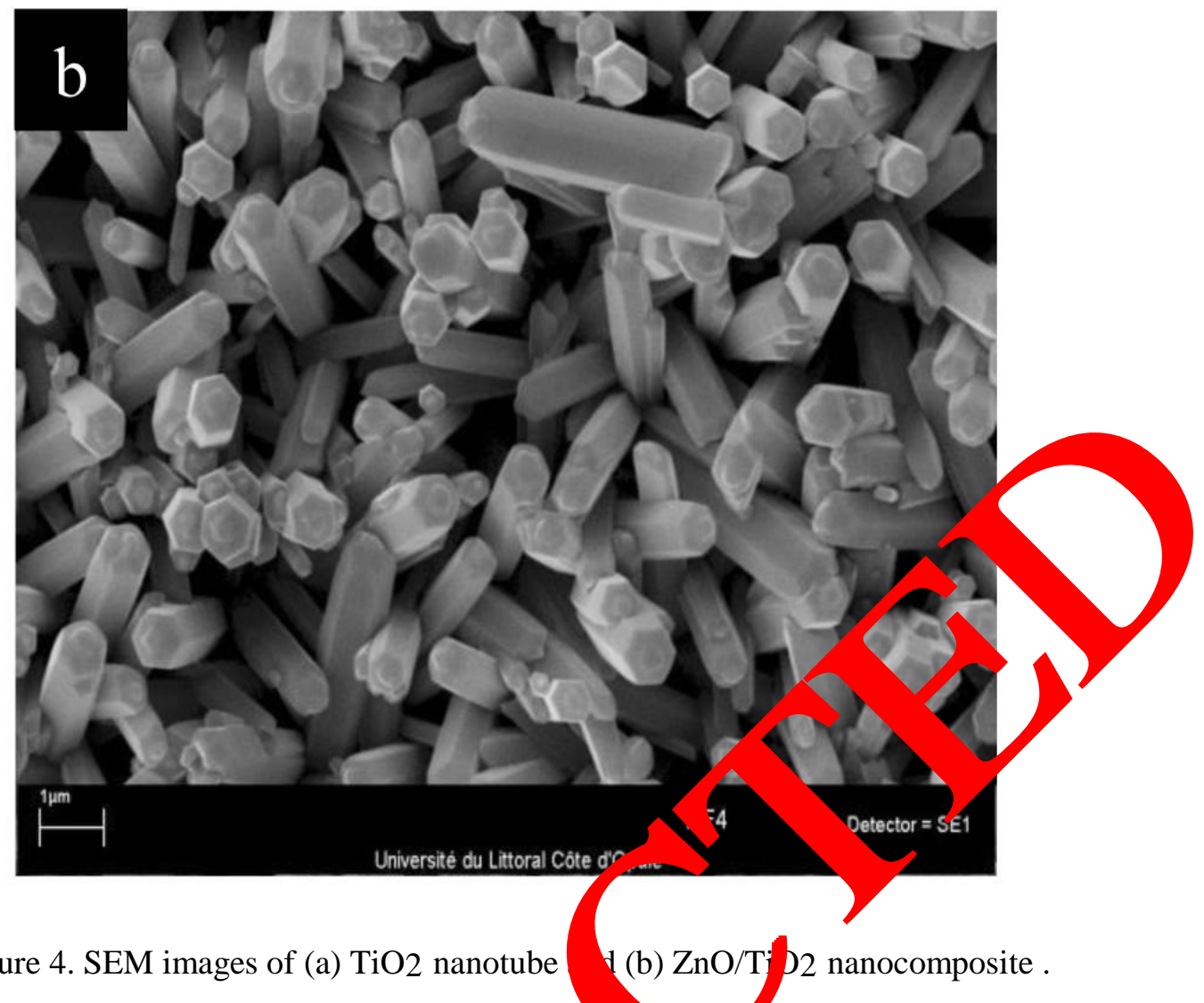

The SEM image of the $\mathrm{TiO}_{2}$ nanotube formed $\mathrm{O}_{2}$ substrate by anodization method shown in Figure 4 a, which reveals that high de s. ordered and uniform nanotubes array are formed.

The diameters of these nanotub ange fro $60 \mathrm{~nm}$ to $95 \mathrm{~nm}$ and their length is about 1.7 $\mu \mathrm{m}$ detected by pofilometry.

After $\mathrm{ZnO}$ deposition by the $\mathrm{ZnO}$ grows oriented th ough the 22 NTs inner channels. The epitaxial growths of $\mathrm{ZnO}$ nanorods inside the $\mathrm{TiO}_{2}$ notube ch Mels are spilled over the $\mathrm{TiO} 2$, which is in good agreement with one re rrted Z. Zhang et al [20] and K. Yu et al [23].

\section{CONCLUSION}

$\mathrm{ZnO} /$ titano nar ocomp sites were fabricated via two step route. The $\mathrm{TiO} 2$ nanotubes were fabricated $b$, nodiza on method. The hydrothermal process was employed to form $\mathrm{ZnO}$ nanorod $1 \mathrm{TiO} 2$, of chara rized by differ at techniques: XRD, and SEM. TiO2 nanotubes are mainly anatase structu $n$ dered. The diameter of these nanotubes ranges from 60 to $95 \mathrm{~nm}$ and the length is ut $1.7 \mu \mathrm{m}$. The $\mathrm{ZnO}$ nanorods have high crystallinity of wurtzite hexagonal structure.

\section{ACKNOWLEDGMENT}

This work was supported by Ceramic Laboratory of Physic department, University of Constantine, Algeria. The authors are grateful to J. Carru of Calais University, France, and O. Abdelkader of Cadi Ayyad University, Morocco for their help in using the Scanning electron microscope. 


\section{References}

[1] J.B. Chen, C.W. Wang, B.H. Ma, Y. Li, "Field emission from the structure of wellaligned TiO2/Ti nanotube arrays," Thin Solid Films, vol 517, p. 4390, 2009.

[2] J.B. Lee, H.J. Kim, S.G. Kim, C.S. Hwang, S.H. Hong, Y.H. Shin, "Deposition of ZnO thin films by magnetron sputtering for a film bulk acoustic resonator," Thin Solid Films, vol 435, p. 179, 2003.

[3] M. Zamfirescu, A. Kavokin, B. Gil, G. Mapluech, M. Kaliteevski, "ZnO as a material mostly adapted for the realization of room-temperature polariton lasers," Phys. Rev, vol B 65, 161205 , p. 1, 2002.

[4] Y. Wu, H. Yan, M. Huang, B. Messer, J.H. Song, P. Yang, "Inorganic Cermm uctor Nanowires: Rational Growth Assembly, and Novel Properties," Chem. Eu vol J 8, p. 60, 2002.

[5] Y.F. Mester, L.L. Zamora, J.M. Calatayud, "Flow-chemiluminescence. a growing ddity of pharmaceutical analysis,” Luminescence, vol 16, p. 213, 2001.

[6] C.J. Lee, T.J. Lee, S.C. Lyu, Y. Zhang, H. Ruh, H.J. Lee, "Fi ra mis from well-aligned zinc oxide nanowires grown at low temperature," App. Ph ett, Vol $\delta$ s648, 2002.

[7] Q. Wan, Q.H. Li, Y.J. Chen, T.H. Wang, X.L. H P. L. C.L. Lin, "Fabrication and ethanol sensing characteristics of $\mathrm{ZnO}$ nanowire as sonsors,"
3656, 2004.

[8] Z.L. Wang, J.H. Song, Science, Vol. 412, pp. 242 46, 2006.

[9] C. Levy-Clement, R. Tena-Zaera, M.A Ryan, A. G. Hodes, "CdSe-Sensitized pCuSCN/Nanowire n-ZnO Heterojunctions, -Mater, vol 17, p. 1512, 2005.

[10] Y. Zhang, N. Wang, S. Gao, R. He, S. Mio, ymple method to synthesize nanowires," Chem. Mater, vol 14, p. 3564, 20

[11] D. Banerjee, J.Y. Lao, D.Z Jang, I.Y. Hua g, Z.F. Ren, D. Steeves, et al, "Large-quantity free-standing ZnO nanowi _ett 83, p. 2061, 2003.

[12] S.Y. Li, C.Y. lee Y. Tseng, Cryst, "Copper-catalyzed $\mathrm{ZnO}$ nanowires on silicon (1 0 l 0 ) grown by por- id-solid process," Cryst Growth, vol 247, p. 3572, 2003.

[13] J.J. Wu, S C. Liu, "Lo "mperature Growth of Well-Aligned ZnO Nanorods by Chemical V or De sition," Xdv. Mater, vol 14, p. 215, 2002.

[14] P.C. Chang, an, D. Jang, W.Y. Tseng, W.A. Chiou, J. Honget, et al., "ZnO Nanowires Syntb by or Trapping CVD Method," Chem. Mater, vol 16, p. 5133, 2004.

[15] Zh ng, L.D. Lhang, G.H. Li, W.Z. Shen, "Fabrication and optical properties of largescalc coxide nanowire arrays by one-step electrochemical deposition technique," Chem. s. Lett, vol 363, p. 123, 2002.

[16] L.E. Gkene, L.M. Law, J. Goldberge, F. Kim, J.C. Johnson, Y. Zhang, et al., "LowTemperature Wafer-Scale Production of ZnO Nanowire Arrays," Chem. Int. Ed, vol 42, p. 3031, 2003.

[17] J. Goldberger, R. He, S. Lee, Y. Hang, H. Yan, H. Chio, P. Yang, "Single-crystal gallium nitride nanotubes," Nature, vol 422, p. 599, 2003.

[18] J. Hwang, B. Min, J.S. Lee, K. Keem, S. Kim, "Al2O3 Nanotubes Faricated by Wet Etching of ZnO/Al2O3 Core/Shell Nanofibers,” Adv Mater, vol 16, p. 422, 2004. 
[19] S.I. Na, S.S. Kim, W.K. Hong, J.W. Park, J. Jo, Y.C. Nah, T. Lee, D.Y. Kim, "Fabrication of $\mathrm{TiO} 2$ nanotubes by using electrodeposited $\mathrm{ZnO}$ nanorod template and their application to hybrid solar cells," Electrochim. Acta, vol 53, p. 2560, 2008.

[20] Z. Zhang, Y. Yuan, L. Li, Y. Cheng, "Preparation and photoelectrocatalytic activity of $\mathrm{ZnO}$ nanorods embedded in highly ordered $\mathrm{TiO} 2$ nanotube arrays electrode for azo dye," Journal of Hazardous Materials, vol 158 p. 517, 2008.

[21] N. Wang, X. Li, Y. Wang, Y. Hou, X. Zou, G. Chen, "Synthesis of ZnO/TiO2 nanotube composite film by a two-step route," Materials Letters, vol 62, p. 3691, 2008.

[22] J.B. Chen, C.W. Wang, B.H. Ma, Y. Li, J. Wang, "Field emission from the structure of well-aligned

[23] K. Yu, Z. Jin, X. Liu, J. Zhao, J. Feng, "Shape alterations of ZnO na crystal an Is fabricated from NH3·H2O solution," Applied Surface Science, vol 253, p. 407. 007.

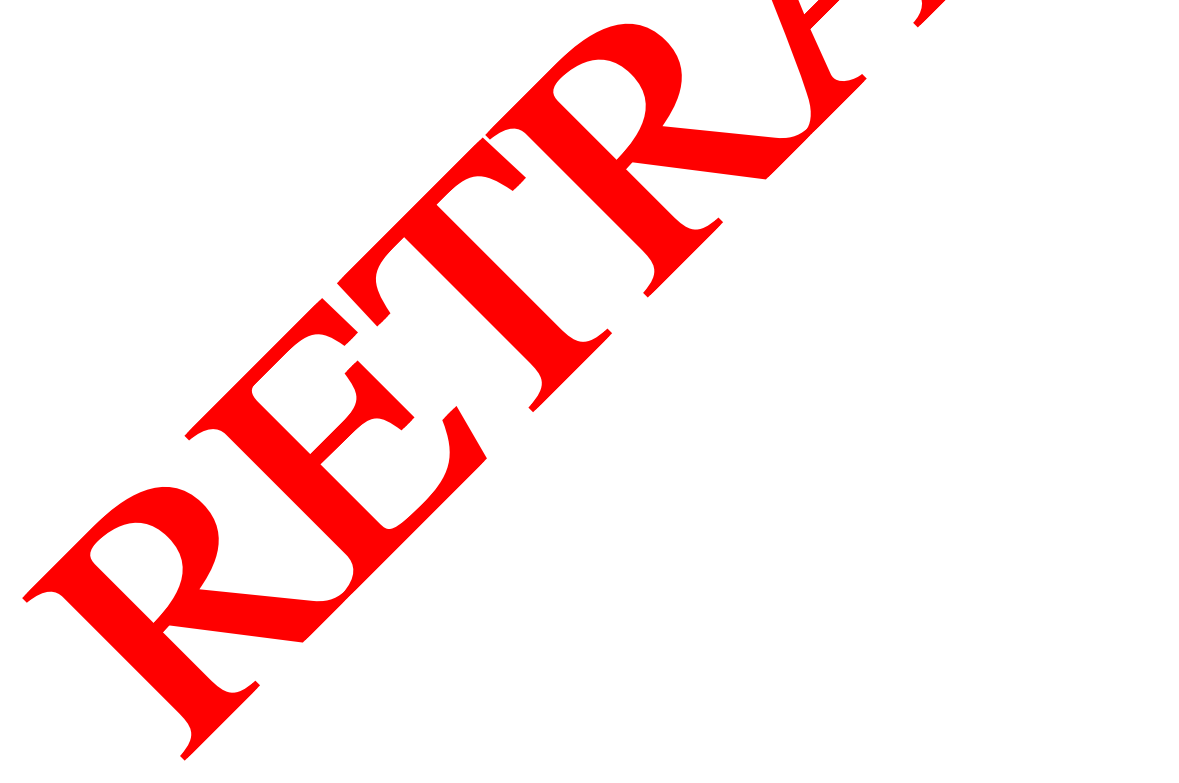

